\title{
Celebrating Teej as a Festival of (Re) union and Enjoyment
}

\author{
Kamala Dahal, $\mathrm{PhD}^{*}$
}

\begin{abstract}
Among many festivals that are celebrated in Nepal, Teej, is regarded as the most significant festival observed by women. If we trace its origin as Parvati's union with Shiva after her long and hard penance, then we understand that it is the festival celebrated in memory of the victory of a wife's love and devotion towards her husband. If we observe the way it is celebrated today, then we come to understand that it is a festival celebrated as an occasion of (re) union with parents, bothers, and sisters in their maternal home and sense of joy and happiness. In Nepal and in most parts of North India women gather at their maternal home, have delicious meals, sing and dance with full sense of freedom and enjoyment during the occasion. Women can also express their feelings of pain and suffering which they have to bear at their inlaw's house in the form of singing and dancing through which their burdens lightened. While some people still celebrate Teej as a religious ritual in ancient sense, many other people today celebrate it as an aspect of cultural life in modern sense. Despite different views and opinions about Teej, it has been an integral part of life of women in Hindu society of South Asia and beyond. This article explores how this festival provides a sense of joy and happiness to women to the women who are subjugated by patriarchal domination in Nepalese society and are free to reunite with maternal home and family and enjoy fully, if only during this occasion. It is based on the secondary sources and field study.
\end{abstract}

Key words: Teej, festival, fasting, enjoyment, celebrate, devotion

\section{Introduction}

As Jatras, feasts, and festivals are considered as integral parts of (Khatri and Dahal, Nepali culture 2053: 129), Teej is regarded as an important festival mostly celebrated in Nepal and North India. Migrant women who live in different parts of the world also celebrate Teej as a cultural part of their life because they want to keep core values of their root culture.

\footnotetext{
* Dr Dahal has been working as the Associate Professor of Culture at Patan Multiple Campus, Tribhuvan University, Nepal.
} 
There are different festivals with the name of Teej. Teej is a generic name for a number of Hindu festivals that are celebrated by women mainly in this region. They are named differently in terms of season, location, and a particular community culture. Some of the popular names are as follows:

Akha Teej is the local name of Akshaya Tritiya which falls on Baisakh where as Hariyalee Teej is celebrated on the third day of the bright lunar fortnight of the month of Shrawan. As the name suggests, Hariyalee Teej is mainly related with greenery and commemorate it for abundance of greenery and good harvest. Women wear green colored clothes especially, sarees, wear green bangles and adorn their hands with beautiful mehndi patterns which resemble green nature. The name Hariyalee is given to the festival as the month of Shrawan marks the season of greenery. It is also called small Teej or Teej of Shrawan.

Kajari Teej is a Teej festival celebrated on the third day of the dark lunar fortnight of the month of Bhadra. The word Kajari indicates folk songs, which are commonly sung in the months of Shrawan and Bhadra mostly in rural areas of India. Women celebrate the festival praying to Shiva, Parvati, Ganesh and Krishna singing Kajari songs. As on the day of other Teej festivals, women undergo fasting wishing the long life and happiness of their husbands on this day also. Gauri Tritiya is a Teej festival that is celebrated on Tritiya day according to the lunar calendar. Women mostly worship Goddess Gauri so the Teej festival has got the name Gauri Tritiya. On this occasion also they worship deities and celebrate it as a part of religious and cultural life.

Haritalika Teej is the biggest of the many varieties of Teej festivals that are celebrated on Shukla Paksha Tritiya Tithi of Bhadrapada month (third day of the bright lunar fortnight of the month of Bhadra (August or September) in Solar Calendar. Haritalika Teej comes one month after Hariyalee Teej and is mostly celebrated one day before Ganesh Chaturthi. This is the festival which is solely dedicated to women and exclusively celebrated by the women. This festival falls in the mid monsoon so it is also called Monsoon Festival. This is the day when women undertake fasting for their husbands' long life and happiness.

Basically this article in the following paragraphs delineates two things. First it tries to trace the origin and development of the Teej festival. Second, it explores how this festival is celebrated by women in contemporary Hindu society. More specifically, the following paragraphs deal with different stories about the of Teej, origin, especially Haritalika Teej, popular in this region and how it has become an integral part of life among women in Hindu society. It also explains how women enjoy this festival with the sense of full freedom from household chores at least for three days. 


\section{Tracing the Origin of Teej}

One of the problems for understanding the traditional festivals celebrated in Nepal, either the national festivals or the regional ones, is that we are not in a position to trace the history of their exact origin due to the lack of authentic information. The same case is applicable to the Teej festival also. There is no adequate evidence to suggest the origin of Teej because neither the ancient religious texts nor the eighteen Puranas have the references to this festival. So, some scholars opine that the word Teej does not come from Sanskrit (Kaudinyayan, 2045: 713). But some other writers state that Mahabharat, Shiva Purana and Brataraj have some references indicating the performance of haritalika vrat by Goddess Parvati (Paudyal, 2070), which can be linked in some way to the present state of Teej.

There are different myths and legends about the use of the word Haritalika which later became the name of a festival. Haritalika is the classical name of the one type of Teej festival. According to a legend, Goddess Parvati had accepted Lord Shiva as her husband and started to please him through devotion and praying since her childhood. Parvati was shocked when she knew about her decision. Then she decided to take help from one of her friends who took her to a dense forest to hide for some time to avoid her marriage with Lord Vishnu.

From then on, she led an ascetic life. She went through hardcore tapasya (penance) and had to take 108 births on the earth having failed to have Lord Shiva as her husband till 107th birth. On her 108th birth, when she continued the hard-core tapasya again, Shiva realized her devotion and decided to test her sincerity. On the third day of the month of Bhadrapada, when Parvati made a Shiva lingam using her hair and prayed to Shiva, He then disguised as the rich Vishnu and rode a gorgeous carriage to see Parvati, trying to lure her to marry him. But, Parvati remained unmoved by this. So Shiva was very impressed by her determination and finally revealed his identity as Shiva to marry her.

Goddess Parvati and Lord Shiva married her with her father's blessings. It is commonly believed that it was Alika who helped Parvati to escape from the house and hide in an unknown forest. The 'Harat', in Sanskrit means 'abduction' and 'Aalika' means a female friend. So, the festival got name harit+ alika = Haritalika (Acharya, 2045: 115). But the festival in Nepal is commonly called Teej Parva.

According to this age-old legend, Goddess Parvati was reunited with Lord Shiva on the third day of the bright lunar fortnight of the month of Bhadra. So, it is believed that Goddess Parvati recognized this moment to be highly auspicious for womenkind and proclaimed that whoever invoked her on this day would be blessed with happy married life and would have their wishes fulfilled. It is also said that Hartalika Teej was 
narrated by Lord Shiva Himself who reminded Parvati of her incarnation as Shailputri in the house of King Himalaya Raj.

According to another legend, Teej is a small red insect that comes out of the soil during the rainy season. It is said that Teej got its name from the same red insect. This is how why Teej is celebrated in red clothes. However, this view of red insect is not acceptable as some other festivals celebrated in spring season are also named Teej. For example, the Akshaya Tritiya festival which is celebrated in spring season is addressed as $A k h T e e j$ in India.

Most of the scholars in Nepal and India opine that Teej is the corrupt form of Tritiya. The Nepali Brihad Shabdakosh (2040:602) and other Shabdakosh (Nepal, 2057:616) took 108 births on earth state that Teej is the corrupt form of Tritiya. Some of the foreign writers also have used the word Tritiya to address Teej (Shrivastava, 1981:95). This view is more convincing because when local languages started to develop in Nepal, the Sanskrit word Tritiya changed into Teej.

In the context that we have to depend on myths and legends, it is important to note that Teej festival was celebrated even in Vedic, Puranic, and other ancient historical periods. We can find that some of the books of later period, such as Dharma Sindhu, Dharmashastra Nibanda Niryanasindhu, barsikkritya granth as well as some books of the medieval period in manuscript forms, preserved in the National Archives, have some references to Haritalika Teej festival. It can thus fairly be argued that the Teej festival originated in ancient times, became popular in medieval period, and gained its popular currency in modern times.

\section{Celebrating Teej in Nepal}

There are different rituals of Teej festival performed in Nepal. Attired mostly in traditional red sarees women congregate in a temple to worship Lord Shiva and Goddess Parvati. On this day, in some places, idol of Goddess Parvati is decorated with rich silk cloth and heavy jewelry. This day is considered as very important day because married women and engaged girls stay fasting praying for the long and healthy life of their husband and to-be-husband. So, both married and unmarried Hindu women observe the three-day-long festival seeking blissful married life and happiness for their husband and to-be husband.

\section{Preparation for Teej celebration}

Teej Puja is celebrated in different steps such as preparation for Teej celebration, dar khane, activities of the main fasting day, and worshipping the goddesses with puja. These steps are detained in the following paragraphs. 
Teej starts about seven days before the main day. Firstly, brothers or fathers of the married sisters or daughters go to invite them to maternal home to celebrate the festival. Secondly, women start shopping for Teej well in advance. This is the very occasion for (re) union with maiti and cheli which abounds with joy, happiness, and merrymaking They buy different things for worshiping and fruits and other food items for Teej feast. They do not miss to buy new clothes and jewelry because Hartalika Teej is the time to adorn oneself with new clothes and jewelry. Thirdly, mothers send customary gift to the homes of their married daughters. The customary gifts include dar food, scarlet sarees, red glass bangles and other valuable things to her daughter and daughter's mother-inlaw separately. Girls engaged to be married receive a gift from their future in-laws on the day before the festival. The gifts include henna, bangles, a special dress, and sweets. Fourthly, they invite their family members, friends and they decide to celebrate the Teej, especially the dar khane programme, together.

\section{The first day of Teej: Dar khane}

On the first day of the three-day celebration of Teej a special feast is served to the women in the house. One of the interesting aspects of the Teej festival is feeding oneself with piecemeal on the preceding day of fasting. The lavish feast taken on the day of Dar. When the night falls, they make a hearty meal and prepare tasty sweets. In the evening group of women- mothers, grandmothers, sisters and daughters including good friends gather together to have a feast, perform dances and sing songs. These celebrations continue till midnight. Some women may hold their feasting party during the day. When the children are sleeping and men out of sight the women often congregate in one room and seat themselves on the floor around a spread of many many dishes, laughing, bantering, and gorging themselves with all they can hold. The feast must be finished before the midnight.

In recent days the forms and practices of merry making have changed. Dar is originally meant to be taken only for one day, that is, on the preceding day of Teej fasting. But these days it has become a different mode where women have started gathering in the name of having Dar even a month before the Dar khane actual day. Previously, in Dar feast a variety of regional / traditional sweet dishes such as kheer, pulao, sel-roti, etc. were included but now varieties of dishes, vegetarian as well as non-vegetarian both, including alcoholic beverages are included in Dar. All kinds of curry- mutton, chicken, fish and eggs, fruits and sweets, vegetables with achar can be seen in Dar feast in these days. The expensive Dar feast tradition often strains the economic burden to the family who are not economically sound. Tradition compels that the husband must meet these expenses even if it means pawning valuables, taking a loan or selling part of his store grains. Thus, some men, alluding to the next 
day's fasting, claim that 'a woman observing her yearly Teej fasting often consumes a whole bushel of corn' (Anderson, 1988:116). This can be taken as a change that engages women in malpractice of Teej.

\section{Activities of the main day of Teej}

A religious text Vratraj gives detailed Vidhi (method) to perform Hartalika Teej Puja. The main puja steps given in Vratraj are as follows:

\section{Taking a bath}

The first step of Teej ritual is taking a bath in the early morning. The auspicious time for Hartalika Teej Puja is the the morning, which the women need to get up early to take a holy bath, intended to purify their souls. The religious text Vratraj prescribes the bath with Sesame and Amalak powder. If possible, the bath should be taken in nearby holy rivers or ponds, though there are no restrictions in showering within the dwelling house.

\section{Attire/dress up}

After the bath, women dress up with new clothes. Adorning with new clothes and ornaments is an important part of the festival as women wear elegant traditional attires, mostly red sarees, red bangles, red bindis and kajal along with applying henna on their hands. Women are usually seen in auspicious red sarees if possible, in their wedding sarees. Some unmarried girls dress up in Kurta-Salwar. Some women wear very heavy jewelry while some wear light jewelry. Women have full liberty to ask for anything they wish. Even their husbands do not stop them from doing anything and offer gift to them as they desire because they starve themselves for the well-being of their husband.

\section{Sankalp (Oath/determination)}

The third step as described in Vratraj is taking Sankalp to perform Haritalika vrat to please the deity Umamahashwar. The Sankalp is individual determination to assure her to successfully complete the fasting. Therefore, the devotee should show her determination and take a Sankalp that 'I am able to celebrate the fasting and vrat, take oath for confidently completing the vrat'. For Sankalp it is not necessary to be lauded or to get help from any other.

\section{Worshiping Lord Ganesh}

The fourth step in Teej vrat is worshiping Lord Ganesh. According to Hindu mythology, Ganesh, is worshiped firstly before worshiping other gods in any worship or 
religious works. Upon failing to do so, it is believed that Puja would be unsuccessful. Thus, Lord Ganesh is worshipped before worshiping Shiva and Parvati in Teej although Teej day is only to show devotion to Shiva and Parvati.

\section{Shodashopachar puja of Shiva- Parvati}

After worshipping Ganesh women visit nearby or famous Shiva temples to pray to God Shiva and Goddess Parvati. If there is no Shiva temple available, handmade idols of Lord Shiva and Goddess Parvati are worshipped and legend of Haritalika is narrated during the Puja. In Kathmandu valley, during the Teej Puja most women like to go to the great temple of Shiva, Pashupatinath temple for the devotion of Shiva as it is believed that the secret phallic symbol (Shiva Linga) of Pashupati represents Shiva himself. On this particular day, the streets of Kathmandu turn into a sea of red colour with women dressed in red Sarees and Dhotis making their way to the Pashupatinath Temple. The Pashupatinath temple is only open to women and priests for that day. They worship and offer fruits, flowers, etc. to Lord Pashupati by dancing and singing the religious songs.

Shodashopachar puja of God Shiva and Goddess Parvati is pivotal ritual of Teej. Women visit Shiva temples to pray to Lord Shiva and Goddess Parvati. They pray for their husbands' longevity, progress, and prosperity. They chant religious hymns, recalling the ordeal Parvati had gone through to win the heart of the master of all living beings (Regmi, 1999: 133).

\section{Worship of Teej Mata - Goddess Parvati}

Teej honors Goddess Parvati as a symbol of utter devotion and love. Hence, in some places, Parvati is also called Teej Mata so Teej is called Teej Mata festival. Teej festivities and its celebrations are dedicated to Goddess Parvati and this is why it is considered as a festival of womenfolk. The divine figure of Parvati is worshiped with full dedication at the time of Teej as said above. Puja is conducted in the afternoon or in the evening of the day or in early morning of the following day. During the field study the researcher found different groups of women performing their Puja at the ornately carved images in Pashupatinath area. Some women are found performing their Puja on the bank of Bagmati River. The main Puja takes place with offerings of flowers, sweets and coins that are supposed to be holy. A semi-circle is created and an idol of Parvati is kept at the centre. A Brahman priest helps them to worship accordingly. On this occasion woman offer flowers, fruits, sweets, 'sindoor' or vermillion, red glass bangles, tika etc. to Goddess Parvati. Women are eager to hear Hartalika Teej Vrata Katha, chant shlokas and mantras to please Lord Shiva and Mata Parvati. All the ladies together worship and listen to the holy Teej 
Katha as the priest narrates. Young girls also sit and listen to the Katha. While listening to the Katha, women are expected to concentrate their minds to their soul mate. The ritual often lasts for two hours.

In the evening of the day the women worship Goddess (Parvati) and offer different things beseeching her blessings upon their husbands. This day is enjoyed with full craze, dance is arranged and women carry pots on their heads and indulge in dance singing songs praising Goddess Parvati. A special puja is also performed to worship the moon. Traditional singing of songs and dance escalate the enthusiasm of Haritalika Teej celebrations. Both married and unmarried women enjoy the festive spirit by swinging on adorned swings and singing songs relating to the month of Sawan. It is also customary to receive beautiful new clothes and ornaments from her Mother-inlaw. Hartalika Teej welcomes the monsoon season and is celebrated primarily by girls and women, with songs, dancing and prayer rituals. Because a friend of Goddess Parvati helped her to get Lord Shiva as her husband, this day is also regarded as the solidarity of friendship among the female friends.

When Puja is complet, women offer fruits, flowers and other holy items and seek blessings from Shiva Parvati for marital bliss. Devotees are granted prasad which she has offered to the gods, usually a banana or other fruits, which her husband is required to eat. She touches his bare toes with her forehead, washes his feet and, according to tradition, is required to drink this consecrated liquid. Then the women are allowed to break their fasting, only after gaining her husband's permission. Another important thing of Teej Puja is the oil that the oil lamp which should be kept alight throughout the night. It can be a sign of bad omen if it extinguishes.

\section{Fasting}

The most important ritual of Teej festival is fasting. Women and unmarried girls keep fasting for long and healthy life of their husbands. Teej fasting begins immediately after Dar khane program at midnight of that day and goes for 24 hours. It is the most rigorous fasting in which not one morsel of food or drop of liquid can be taken for twenty-four hours. Extremely pious women will not even swallow their own saliva. They do it to avoid a sin that is mirrored to drinking their own husbands' blood. Women observe Nishivasar Nirjala Vrat which means that the women not only abstain from food but also avoid drinking water and other liquid for the whole day. According to Bhavishwettar Purana, those who do fasting on this day and fulfill it successfully are sure to gain good grace of god (Deep, 1982: 78). The fasting day is observed with evening prayers and traditional dancing and singing activities. When the daylong fasting for long life of their soul mate is over, women can drink water and eat some food. These days many husbands encourage their wives to drink. 
During the field study the researcher noticed a bit change in the trend of keeping fasting these days. All women may not do rigid fasting as it used to be about 50 years ago. Due to the education and social awareness, women today are beginning to celebrate Teej taking care of their health as well. Some women do 'vrata' or fasting by drinking water or other fruit juice, some by consuming only fruits and some do 'nirjala' vrata without a drop of water and also refrain from sleep. During the Teej, women gather around the holy goddess temple and pay obeisance to the Goddess Devi and God Shiva.

Teej fasting is difficult when women restrict themselves to have even a morsel of food and drop of water for full 24 hours. It is even more difficult for the newlywed women to keep the 24-hour-long fasting without eating and drinking anything. One needs lot of patience and courage to keep such a long fasting. Usually mothers encourage their daughters to drink juice or tea so that they do not fall sick on such an auspicious occasion. These days' husbands suggest that their spouse should not do fasting so rigorously. In the interview some women admitted that they would drink juice as encouraged by their husbands.

Pregnant women are advised not to keep the fasting and even if they do it, they are advised to consult a doctor. Many pregnant women go on a diet of milk and fruits and fulfill their nutritional requirements. At this difficult time of the day women also play a many games, watch movies, and do many other recreational activities to pass their time. It is also found that some even go off to sleep and don't involve themselves in any household activity.

The most interesting thing about fasting is that women are happy even without a morsel of food or a drop of water during the vrata. Despite extreme cases of even without swallowing saliva, women do not care about eating and drinking. This has been a customary practice since long ago.

\section{Rishi Puja}

The last day of Teej is celebrated with a personal holy bathing and worshiping the Sapta Rishi on the day of Rishi Panchami, the fifth day of Shukla Paksh (Waxing Moon Fortnight) in the month of Bhadrapada, as per the Hindu calendar. It falls on the next day of Ganesh Chaturthi. On that day very early in the morning, women take a traditional bath. This is regarded as an act of purification. It is assumed that woman becomes pure from all sins after taking this holy bath. The bathing ceremony is mandatory for all who have undergone the Teej fasting including all females who crossed the puberty.

On the day of Rishi Panchami women in Kathamndu valley go to the holy river to take a bath. Hundreds of them gather near the temple of Teku Dobhan where 
the Bagmati and Vishnumati rivers meet. As a rule, bath must be taken with red mud found on the roots of the sacred datiwan bush. The red mud must be smeared 360 times on different parts of the body, including the hands, elbows, shoulders, knees, feet, and private parts. Then the hair is washed and women sprinkle themselves 365 times with 365 leaves of datiwan shrub, brushing their teeth 365 times with a stalk of the same plant (Acharya, 2045: 127). Using 365 times is the symbol of 365 days or 12 months and bathing, brushing and sprinkling 365 times means her bath, brush and sprinkle cover for the whole 365 days of last year (Koirala, 2052: 94). These herbs are pure and are considered to make the body clean. After bathing, women pay homage to various deities situated on the bank of sacred rivers.

On this day Rishi Puja is arranged. After taking a bath and putting on clean clothes, women make a square shaped diagram (Mandal) at a clean place. Placing the image of Sapta Rishi on the Mandal she pours water and Panchamrit over the image, put tika of sandalwood (Chandan) on their forehead, put on a garland of flowers and offer flowers fruits, sweets, etc. In many regions, this process is done on the riverbank or near a pond. Women do not have cereals after this puja. Rather they take a special type of rice on Rishi Panchami.

Rishi Panchami puja is especially dedicated to the Saptarishi, the seven great sages such as Kashyap, Atri, Bharadwaj, Vishvamitra, Gautama, Jamadagmi and Vashishtha (Acharya, 2045: 127). Sapta Rishis are supposed to be the sages who devoted their lives to the wellbeing of humanity. They taught general people basic principles of goodness of higher level. They were determined to their principles of living better life. It is believed that they handed down their wisdom to the people who are able to follow the path of knowledge and wisdom that they taught. The holy bathing ceremony on Rishi Panchami is supposed to be an atonement of female sin as she might have committed in the last twelve months knowingly or unknowably. It is a strong belief in Hindu society that having undergone this purifying bathing ritual, women are absolved from all sin, real, or emarginated, including that awful transgression of touching a man during menstruation. The Hindu tradition states that women who are under menstruation are forbidden to undertake religious activities or involve themselves in domestic affairs till they return to normal state. They are even prohibited to touch holy things. If this condition is breached by mistake or for other reasons, it leads to Rajaswala Dosh. It is believed that women fast on Rishi Panchami to get rid of this $d o s h$. There are many powerful stories in Hindu mythology explaining the significance of Rishi Panchami which force women to perform bathing ceremony and worshiping the Rishis. Womenfolk believe that Rishi Panchami is the road to peace and sanctification of the soul, mind and body. While so doing women are happy and enjoy the festival with utmost enthusiasm. 


\section{Singing and dancing}

Another notable feature of Teej festival is performing the traditional singing and dancing. It is very interesting that although the womenfolk may be weak from fasting and loss of sleep, they take pride in concealing any ill effects, many laughing, dancing beating the small drums, or singing ancient hymns. As all that the festival used to be the medium to express the feeling traditionally, that the womenfolk today celebrate it even in their husband's houses through the lyrical melodies which they sing and dance. So, the womenfolk are seen in the street corner singing and dancing different types of songs relating to the different aspects of their individual, social, and family issues.

Apart from the traditional Pujas and other rituals, women dance on tunes of various Teej songs. It is a traditional way to express their feelings. Women in different parts of the country celebrate Teej by performing their traditional dances. When it is the rainy season, it is assumed that spirits go high in celebration and this is marked with traditional folk dances in Kathmandu valeey. Teej dances in Kathmandu cheer up the people and create a perfect festive mood. Colorfully dressed Nepali women sing various songs and perform folk dances in fairs and temples which become a major part of attraction for foreign tourists.

Nepali women believe that such devotional songs reach the ears of Goddess Parvati who would fulfill their wishes and bless their dear husbands with long and healthy life. For women in Nepal, Teej is the most colorful festival when they wish to celebrate it with utmost devotion to God and Goddess. They believe that traditional dance is the easiest and most enjoyable way to keep up the spirit of the festival. Women dancing in red sarees create the most holistic view at the time of Teej, which is a rare scene.

Currently, musicians and artists are beginning to make cassettes, videos, you tube and other audio-visual materials about Teej. Many songs and dances show women's true feelings, emotions, and sentiments very often with pain and suffering that they have to experience in their in-law's house. But more often than not, some of the articts and musicians demonstrate songs and dances which also show rather vulgar performance in front of the devoted elderly women who initially celebrated Teej praying for the long and healthy life of their husbands.

\section{Conclusions}

On the basis of the details of Teej festival give above we can conclude that Haritalika Teej is by far the most popular festival of women celebrated in Nepal despite variations in different locations. Both in ancient and modern senses, Teej is obviously a festival of (re)union and the enjoyment that results from that 
union and the the way it is celebrated. If we regard this festival in terms of religious myth, it is the festival triumph of woman's love for the desired person to be her husband as Goddess Parvati was able to have her sacred union with God Shiva. In cultural sense, it is regarded as the (re)union of married women with their parents, brothers, and sisters in their maternal home. In both cases faith, love and affection are of paramount importance.

Despite its different names, forms, and nuances in relation to the geographical locations and particular communities that celebrate it, there are common practices of celebrating it among the people. Likewise, there are different steps to be followed by devoted while observing the festival. Among the various forms, types and steps to be followed, Nepali women celebrate Haritalika Teej as an integral part of cultural life. These women are entirely devoted to the deities Shiva-Parvati who they think bless them with blissful life devoid of pain and suffering. The Hindu women, especially from Brahman and Chhetri community, strongly believe that the deities will fulfill their desire for happy and prosperous life. During the festival that is celebrated for three days, they are engaged in having delicious meals before fasting, singing songs and dancing the dances with full joy and sense of freedom. With the changing context even husbands and in-laws help them enjoy in ways they can. In this sense, Teej can be regarded as a festival of (re) union and enjoyment being free from pain and suffering that have been caused by traditional patriarchy.

\section{References}

Acharya, Chetonath Sharma (2045), Hamra Dharmik Chadparva (Our Religious Festivals) Kathmandu: Sanatan Dharma Seva Samiti.

Anderson, Mary M. (1988) Festivals of Nepal, Calcutta: Rupa and Co.

Deep Dhruba Krishna (1982), The Nepal festivals Kathmandu: Ratna Pustak Bhandar Joshi Hariram (2057) Nepali Chadparva (Nepalese Festivals), Lalitpur: Joshi Research Institute.

Joshi Satya Mohan (2039) Nepali Chadparva (Nepalese Festivals) Kathmandu: Royal Nepal Academy.

Khatry, Prem Kumar and Peshal Dahal (2053), Adhunik Nepal ko Samajik Ilthas (Social History of Modern Nepal), Kathmandu: Sajha Prakasan,

Koirala, Kulchandra (2052), Nepali Sanskritik Jatraparva (Nepalese cultural festivals) Kathmandu: Kul Chandra Koirala Memorial Academy

Koudinyaan, Shivaraj Acharya (2045), Vedic dharma Mul Rupama (Vedic religion in original form) Kathmandu: Narayani Devi and others. 
Nepal, Vasant Kumar Sharma (2057), Nepali Shabda Sagar (Nepalese Dictionary), Kathmandu: Bhabha Pustak Bhandar

Regmi, Rishikeshab Raj (1999), Dimensions of Nepali Society and Culture, Kathmandu: SANN research Institute

Shrivastava, Ashok Kumar (1981), Hindu Society in the Sixteenth Century, New Delhi: Milind Publications Pvt. Ltd.

Tod, James, Antiquities of Rajasthan, Quoted in Shrivastava, Ashok Kumar (1981), Hindu Society in the Sixteenth Century New Delhi: Milind Publications Pvt. Ltd. 